\title{
Rare lytic lesions of bone at uncommon locations-A study of 12 cases
}

\author{
S. B. Shivshetty ${ }^{1}$, Ramya B. V.,"*, Anita $\mathrm{AM}^{3}$, Anuradha G. Patil ${ }^{4}$ \\ ${ }^{\mathbf{1}}$ Assistant Professor, ${ }^{2}$ Tutor, ${ }^{3}$ Associate Professor, ${ }^{4}$ Professor \& HOD, Dept. of Pathology MR Medical College, Kalaburagi, \\ Karnataka, India
}

*Corresponding Author:

Email: ramya.beecha@gmail.com

\begin{abstract}
Introduction: Pathological lesions in skeletal system can be viewed radiologically as lytic lesions of bone. They can be either inflammatory conditions or neoplastic lesions. If they are neoplastic it can be again either benign or malignant. On radiological examination the nature of the disease cannot be assessed. Histopathology is the ultimate tool for the final diagnosis of such conditions.

Aims and objectives: The main aim is to study the different lytic bone lesions, uncommon locations at which they can occur and the histopathological features of the same.

Materials and Methods: This study was done at Mahadevappa Rampure Medical College from June 2017 to June 2018 . A total of 12 bone lesions were analysed. Different investigations were done in different cases after radiological examination. The procedures done were fine needle aspiration cytology, bone biopsy and bone excision. Once they were done the specimens were taken for processing and the staining was done. After that histopathological diagnosis was made.

Results: This study included a total number of 12 cases out of which 6 cases (50\%) are between 25 - 50 years of age. Female predominance was observed. The incidence of non-neoplastic lesions was $8.3 \%$ and of neoplastic lesions was $91.67 \%$. In the neoplastic lesions, the benign lesions were $25 \%$, malignant tumours were $41.67 \%$ and metastatic tumours were $25 \%$. Solitary plasmacytoma was most common tumour among malignant tumours. Also secondary metastasis was common among the malignant bone tumours.

Conclusion: Bone tumours are not routinely found in clinical practice. If the presentation is at rare site it is difficult to come to a diagnosis. Though clinical and radiological approach is available, the histopathology can make the correct diagnosis.
\end{abstract}

Keywords: Lytic bone lesions, Uncommon location, Histopathology.

\section{Introduction}

Pathological lesions in the skeletal system can be viewed radiologically as lytic lesions of bone. ${ }^{1}$ They can be either inflammatory conditions or neoplastic lesions. If they are neoplastic it can be again either benign or malignant. On radiological examination the nature of the disease cannot be assessed ${ }^{1 .}$ It is difficult to determine whether that bone lesion is benign or malignant. ${ }^{2}$ The most common benign lesions which can be seen frequently are bone cyst which can be Aneurysmal bone cyst, Fibrous dysplasia and Osteoblastoma. ${ }^{2}$ The most common malignant tumors which are found frequently are Osteosarcoma and Ewing's sarcoma. ${ }^{2}$ Primary carcinoma of bone is found less frequently when compared to bone metastasis. ${ }^{4}$ In human body third most common site of metastatic disease is found to be bone whereas first two places are liver and lung. ${ }^{5}$ Among all the secondary tumors seen, the primary sites usually are found be lung, kidney, thyroid and breast. Many of them produce mainly lytic lesions in bones and few show mixed lytic lesion and a sclerotic reaction. ${ }^{5}$ Primary tumours which are carcinomas more commonly metastasize to bone when compared to sarcomas. ${ }^{5}$

\section{Materials and Methods}

This study has been done in Mahadevappa Rampure Medical College, Kalaburagi. This study comprises of 12 cases in which bone lesions were diagnosed radiologically in one year period (June 2017 to June 2018). They were diagnosed by the surgeons and advised for imaging. On imaging they were diagnosed as different lytic bone lesions pertaining to the cases respectively. After radiological examination they were sent for investigations. Different investigations done were Fine needle aspiration cytology, bone biopsy and excision biopsy. FNAC procedure was done by inserting needle in the lesion and aspirating the material. Once the sample is obtained it is smeared, stained and viewed for diagnosis. In histopathological laboratory, the tissues were grossed and fixed in $10 \%$ formalin and then further processing is done. For bone specimens 3 to $5 \mathrm{~mm}$ thick sections were taken and then decalcification was done by keeping the specimens in nitric acid solution. After that all tissue samples were processed by increasing concentrations of alcohol. Paraffin blocks were prepared and sections were taken. Sections were stained with Hematoxylin and eosin stain. After the total process is completed, the slides were mounted and viewed under microscope for the final diagnosis.

Inclusion criteria: All the bone lesions which occur at rare sites and which are diagnosed in radiology as lytic bone lesions.

Exclusion criteria: Tiny bone biopsies and samples which were inadequate for reporting are excluded from this study. 


\section{Results}

Out of 12 cases, non-neoplastic lesion is 1 case $(8.3 \%)$ and neoplastic lesions are 11 cases (91.67\%).
Among neoplastic lesions benign lesions are 3 cases (25\%), malignant lesions are 5 cases (41.67\%) and metastatic lesions are 3 cases $(25 \%)$ (Table 1$)$.

Table 1: Proportion of different bone lesions

\begin{tabular}{|l|l|l|l|}
\hline \multirow{2}{*}{ Non neoplastic } & \multicolumn{3}{|c|}{ Neoplastic } \\
\cline { 2 - 4 } & \multicolumn{1}{|c|}{ Benign } & \multicolumn{1}{|c|}{ Malignant } & \multicolumn{1}{c|}{ Metastatic } \\
\hline Madhuramycosis-01 & $\begin{array}{l}\text { Aneurysmal bone cyst- } \\
01\end{array}$ & $\begin{array}{l}\text { Langerhan cell } \\
\text { histiocytosis-01 }\end{array}$ & $\begin{array}{l}\text { Metastasis from breast } \\
\text { carcinoma-01 }\end{array}$ \\
\hline & Fibrous dysplasia-01 & $\begin{array}{l}\text { Fibroblastic } \\
\text { osteosarcoma-01 }\end{array}$ & $\begin{array}{l}\text { Metastasis from renal } \\
\text { cell carcinoma-01 }\end{array}$ \\
\hline & Chondroblastoma-01 & $\begin{array}{l}\text { Malignant fibrous } \\
\text { histiocytosis-01 }\end{array}$ & $\begin{array}{l}\text { Metastasis from } \\
\text { follicular carcinoma } \\
\text { thyroid-01 }\end{array}$ \\
\hline Total-01 & 03 & $\begin{array}{l}\text { Solitary } \\
\text { plasmacytoma-02 }\end{array}$ & 03 \\
\hline
\end{tabular}

The different Non neoplastic lesions included in this study are 1 case of Maduramycosis( $8.3 \%)$.

Benign lesions included in this study are Aneurysmal bone cyst - 1 case $(8.3 \%)$, Fibrous dysplasia -1 case $(8.3 \%)$, Chondroblastoma -1 case $(8.3 \%)$. Malignant lesions are Langerhans cell histiocytosis - 1 case $(8.3 \%)$, Fibroblastic osteosarcoma - 1 case $(8.3 \%)$, Malignant fibrous histiocytosis -1 case $(8.3 \%)$ and
Solitary plasmacytoma - 2 cases $(16.67 \%)$, Metastatic lesions are 3 cases, 1 case of Metastasis from breast carcinoma $(8.3 \%), 1$ case of Metastasis from renal cell carcinoma $(8.3 \%), 1$ case of Metastasis from follicular carcinoma thyroid.

Out of 12 cases, 5 cases $(41.67 \%)$ were male and 7 cases $(58.33 \%)$ were female, showing female preponderance (Table 2).

Table 2: Gender distribution

\begin{tabular}{|l|c|c|c|c|}
\hline \multirow{2}{*}{ Bone lesions } & \multirow{2}{*}{ Non neoplastic } & \multicolumn{3}{|c|}{ Neoplastic } \\
\cline { 3 - 5 } & & Benign & Malignant & Metastatic \\
\hline Male & 00 & 02 & 01 & 02 \\
\hline Female & 01 & 01 & 04 & 01 \\
\hline Total & 01 & 03 & 05 & 03 \\
\hline
\end{tabular}

Out of 12 cases, 3 cases $(25 \%)$ were below 25 years age group, majority of the cases were between $25-50$ years constituting 6 cases $(50 \%)$ and 3 cases $(25 \%)$ were more than 50 years. (Table 3 )

Table 3: Age wise distribution

\begin{tabular}{|l|c|c|c|c|c|}
\hline \multirow{2}{*}{ Age (yrs) } & \multirow{2}{*}{$\begin{array}{c}\text { Non } \\
\text { neoplastic }\end{array}$} & \multicolumn{3}{|c|}{ Neoplastic } & Total \\
\cline { 3 - 6 } & 00 & 01 & 02 & 00 & 03 \\
\hline$<25$ & 01 & 02 & 02 & 01 & 06 \\
\hline $25-50$ & 00 & 00 & 01 & 02 & 03 \\
\hline$>50$ & 01 & 03 & 05 & 03 & 12 \\
\hline Total & &
\end{tabular}

Table 4: Distribution of lesions according to the site involved

\begin{tabular}{|l|l|c|c|}
\hline \multicolumn{1}{|c|}{ Bone involved } & \multicolumn{1}{|c|}{ Lytic lesions } & No of cases & Total \\
\hline Frontal bone & Fibrous dysplasia & 01 & $02(16.6 \%)$ \\
& Langerhan cell histiocytosis & 01 & \\
\hline Clavicle & Aneurysmal bone cyst & 01 & $01(8.3 \%)$ \\
\hline Ulna & Langerhan cell histiocytosis & 01 & $01(8.3 \%)$ \\
& Solitary plasmacytoma & 01 & $02(16.6 \%)$ \\
& Follicular carcinoma thyroid & 01 & \\
& metastasis & & \\
\hline Femur & Chondroblastoma & 01 & $04(30 \%)$ \\
& Osteosarcoma & 01 & \\
& Malignant fibrous & & \\
& histiocytoma & & \\
\hline
\end{tabular}




\begin{tabular}{|l|l|c|c|}
\hline & Breast carcinoma metastasis & 01 & \\
\hline Tibia & Solitary plasmacytoma & 01 & $02(16.6 \%)$ \\
& Breast carcinoma metastasis & 01 & \\
\hline Fibula & Renal cell carcinoma & 01 & $01(8.3 \%)$ \\
& metastasis & & \\
\hline Calcaneum & Maduramycosis & 01 & $01(8.3 \%)$ \\
\hline
\end{tabular}

In our study the most common bone involved is femur with 4 cases (30\%), next is the frontal bone, ulna and tibia with 2 cases (16.67\%) each. Other bones involved are clavicle, humerus and fibula with 1 case (8.3\%) each.

Table 5: Concordance between FNAC and histopathological diagnosis

\begin{tabular}{|c|l|l|c|}
\hline S.No & FNAC diagnosis & Histopathological diagnosis & Concordance \\
\hline 1. & Plasmacytoma & Solitary plasmacytoma & $100 \%$ \\
\hline 2. & $\begin{array}{l}\text { Langerhans cell } \\
\text { histiocytosis }\end{array}$ & Langerhans cell histiocytosis & $100 \%$ \\
\hline
\end{tabular}

In this study in 2 cases fine needle aspiration cytology was done. The procedure of FNAC was followed and the sample obtained is smeared, stained and viewed under microscope for diagnosis. They were diagnosed as plasmacytoma and Langerhans cell histiocytosis on FNAC. Later the biopsy was performed and sent for histopathological examination. This biopsy sample was processed and final slides were reviewed for the diagnosis. They were confirmed as Solitary plasmacytoma of tibia and Langerhans cell histiocytosis of humerus respectively. So the concordance between FNAC and histopathology in this study is found to be $100 \%$.
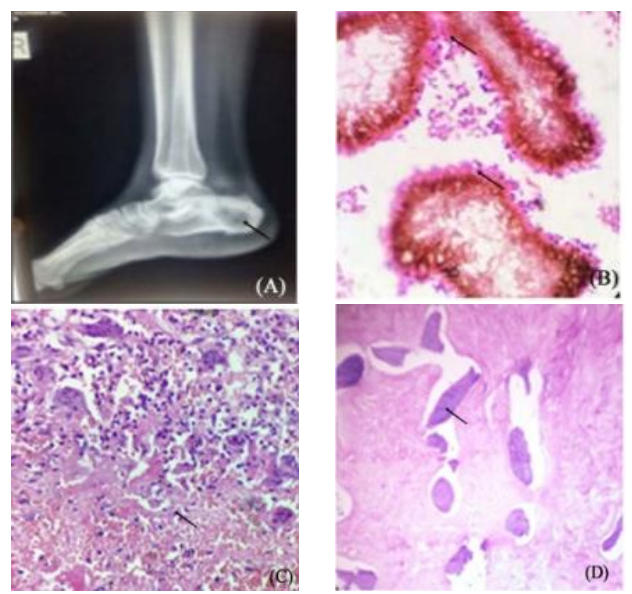

Fig. 1: (A) X ray of right ankle-osteomyelitis; (B): Maduramycosis H \& E 100x, (The outer surface and matrix of the colonies are covered by eosinophilic homogenous material some-times with radiating/knobby extensions); (C): Aneurysmal bone cyst H \& E 40x; (cystic space filled with haemorrhage); (D): Fibrous dysplasia H \& 40x, (chinese letter pattern of osteoid)

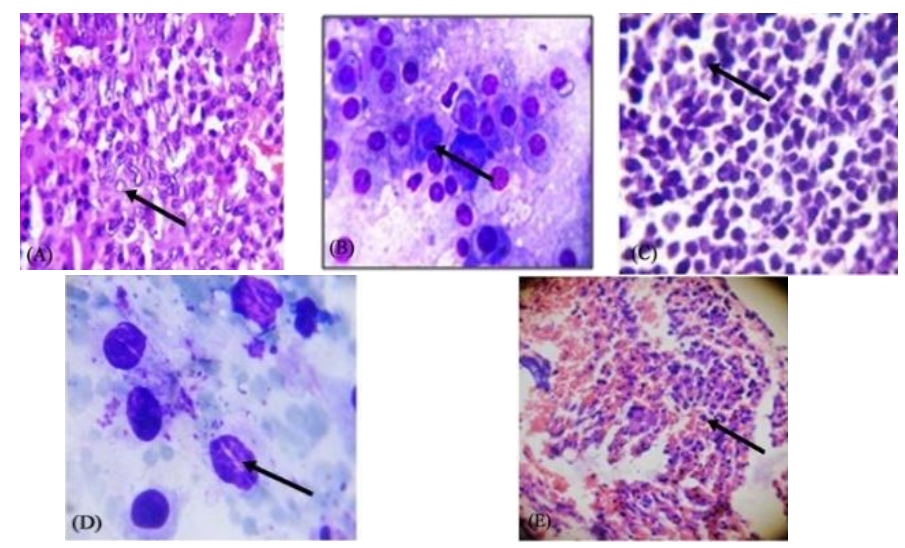

Fig. 2: (A): Chondroblstoma of left femur H \& E 40x (Osteoblasts with abundant pink cytiplasm along with chicken wire matrix surrounding it; (B): Solitary plasmacytoma of tibia FNAC- Giemsa 40x, (plasmablasts, 
mature and immature plasma cells); (C): Solitary plasmacytoma of tibia $\mathrm{H} \& \mathrm{E} 40 \mathrm{x}$ (plasmablasts, mature and immature plasma cells); (d): Langerhan cell histiocytosis of lower end of femur FNAC giemsa 100x showing nuclear grooving in cells; $(E)$ : Langerhan cell histiocytosis of lower end of femur $\mathrm{H} \& \mathrm{E}$ 40x (ploygonal Langerhans cells with eosinophilic cytoplasm, oval nuclei with grooves)



Fig. 3: (A) \& (B): Fibroblastic osteosareoma of lower end of femur H \& E 10x, H \& E 40x (spindle cells with minimal matrix, giant cells seen in stroma); (C): Malignant fibrous histiocytosis of lateral condyle of femur $\mathbf{H}$ \& E 40x (histiocyte like cells, giant cells inflammatory infiltrate seen); (D) \& (E): Male breast carcinoma metastasis to bone (femur \& tibia) CT Scan- right femur and right tibia shows diffuse per-meative destruction of femur, $\mathrm{H} \& \mathrm{E} 40 \mathrm{x}$ ductal epithelial cells seen in bone biopsy
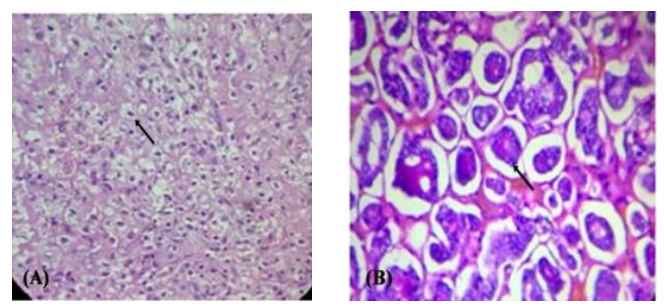

Fig. 4: (A): Renal cell carcinoma metastasis to fibula H \& E 40x, metastatic cells with clear cytoplasm; (B): Follicular carcinoma of thyroid metastasis to ulna H \& E 40x. thyroid follicles seen

\section{Discussion}

Pathological lesions in skeletal system can be viewed radiologically as lytic lesions of bone. They can be either inflammatory conditions or neoplastic lesions. ${ }^{1}$ Age of the patient is an important consideration as few conditions are common in children and few are common in adult age group. History of any pre-existing conditions is also an important feature. ${ }^{2}$

In our study majority of the cases are neoplastic lesions and one case $(8.3 \%)$ was non neoplastic. Total neoplastic cases are 11 cases $(91.67 \%)$ among which benign are 3 cases (25\%), malignant tumours are 5 cases (41.67\%) and metastatic are 3 cases (25\%).

The non-neoplastic lesion included in this study is 1 case of Maduramycosis. The neoplastic lesions were divided into 3 categories. They are Benign, Malignant and Metastatic. The benign lytic lesions included were 1 case of Aneurysmal bone cyst, 1 case of Fibrous dysplasia and 1 case of Chondroblastoma. The malignant lesions are 1 case of Langerhans cell histiocytosis, 1 case of Osteosarcoma, 1 case of Malignant fibrous histiocytoma and 2 cases of Solitary plasmacytoma. The metastatic lesions included are 1 case of male breast carcinoma metastasis to femur and tibia, 1 case of renal cell carcinoma which metastasized to fibula, 1 case of follicular carcinoma thyroid metastasis to ulna. All these cases with this particular diagnosis are found at rare sites respectively.

Out of 12 cases included in the study, 5 cases $(41.67 \%)$ were male and 7 cases $(58.33 \%)$ were female, showing female preponderance (Table 2).

In our study the site of bone which is most commonly involved is femur with 4 cases (30\%), next is the frontal bone, ulna and tibia with 2 cases (16.67\%) each. Other bones involved are clavicle, humerus and fibula with 1 case $(8.3 \%)$ each.

Maduramycosis is also known as Mycetoma pedis or Madura foot. This condition was first described by a scientist Gill in the year 1842. ${ }^{6,7}$ The causative agents include either Eumycetoma or Actinomycetoma. ${ }^{6,7}$ Eumycetoma is a true fungi and Actinomycetoma is a filamentous bacteria. It is a suppurative infection. Microscopically it contains granulation tissue along with discharging sinuses. This is followed by bone involvement as the disease progresses. ${ }^{6}$ Early diagnosis is difficult because it is similar to chronic bacterial infection. ${ }^{6}$ 
Aneurysmal bone cyst was named by Jaffe and Lichtenstein. It is more commonly seen in patients in first two decades of life. It may occur in any portion of the skeleton. Radiologically it is seen as radiolucent or lytic lesion which is eccentrically located and expanded in bone. Grossly it appears like a spongy mass with large blood filled cystic spaces separated by fibrous septa and the margins are well defined. Shell of reactive periosteal bone can be seen. Microscopically blood filled spaces are seen which are lined by fibrous septa and also contain osteoblast like giant cells and osteoid. ${ }^{3}$

Fibrous dysplasia was first described by Lichtenstein in 1938. It is also known as osteitis fibrosa or generalized fibrocystic disease of bone. It is seen in both the sexes equally. Most common site affected is the jaw. Two forms of fibrous dysplasia are known monostotic form and polyostotic form. Radiologically it is seen as intramedullary radiolucency. It can be eccentric lesion or can involve whole of the bone. Microscopically it is seen as a well circumscribed, sharply delineated lesion lined by lamellar bone. Fibrous tissue with proliferation of spindle cells can be seen. ${ }^{3}$ It is also described as Chinese letter pattern. ${ }^{1,3}$

Chondroblastoma is benign in nature. It is a neoplasm which produces cartilage. Most common site is the epiphysis of bones. It is also known as Calcifying giant cell tumour or epiphyseal chondromatous giant cell tumour. It accounts for less than $1 \%$ of all bone tumours. ${ }^{8}$ Microscopically seen are the chondroblasts arranged in sheets, they are round to polygonal in shape with slightly eosinophilic cytoplasm. Also seen are osteoclast type giant cells. ${ }^{8}$

Plasma cell myeloma is a monoclonal neoplastic proliferation of plasma cells. Solitary plasmacytoma of bone is a variant of plasma cell myeloma. It most commonly occurs in $6^{\text {th }}$ and $7^{\text {th }}$ decades of life. Both the sexes are equally affected. The bones which can be more frequently involved are vertebrae, ribs, skull and pelvis. Microscopically it shows a rich vascular pattern with tumour cells surrounding vascular channels. The cells are with eccentric round to oval nucleus, speckled chromatin and abundant cytoplasm. Mott cells or Russel bodies may also be seen. ${ }^{8}$

Langerhan cell histiocytosis is a clonal process. It is also known as Histiocytosis X, Letterer-Siwe disease, Eosinophilic granuloma of bone. It is a rare disease and more commonly occurs in males when compared to females. Most commonly affected bones are flat bones specially skull. Microscopically, cells are arranged in loose cohesive clusters. Cells are large round to oval in shape with oval to indented nuclei and abundant pale eosinophilic cytoplasm. These are histiocytes and nuclear grooving will be seen. Acute inflammatory infiltrate of eosinophils can be seen. ${ }^{3}$

Osteosarcoma is primary intramedullary high grade malignant tumour, in which neoplastic cells produce osteoid. There are many variants of which Fibroblastic osteosarcoma is one. ${ }^{8}$ It usually occurs between $10-25$ years of age. ${ }^{2}$ It can arise in any bone of the body. ${ }^{2}$ The main microscopic feature of this is presence of spindle cells which show malignancy and minimal amounts of osseous matrix with or without cartilage. ${ }^{8}$

Malignant fibrous histiocytoma was first described in bone by Feldman and Norman in 1972. It is also known as Malignant histiocytoma, Xanthosarcoma, Malignant fibrous xanthoma, Fibroxanthosarcoma. It accounts for less than $2 \%$ of all primary malignant bone lesions. Microscopically it consists of mixed population of cells which include spindle cells, histiocytoid cells, pleomorphic cells, giant cells and chronic inflammatory cells. Mitosis are present. Storiform pattern is seen in fibroblastic areas. Many histological subtypes are seen. ${ }^{8}$

Metastasis when found, one should know that the skeletal system is the third common site involved. Clinical features seen in metastatic conditions are pain, pathological fractures and hypercalcemia. Most common symptom among these is pain. Pain is due to periosteal stretching by the tumour along with nerve stimulation in the endosteum. Pathological fracture is the most common finding in conditions where the metastasis is from breast. ${ }^{2}$ Metastatic carcinoma usually involves vertebra, femur, sternum and pelvis. Bone scintigraphy covers the whole skeleton, so it is the most sensitive method for the detection of metastasis. Involvement of skeletal sites can be known by the location of the primary tumour and pattern of blood flow. Grossly metastasis from breast are greyish white and firm, from renal cell carcinoma are soft, hemorrhagic deposits. ${ }^{8}$

\section{Conclusion}

In this study, we have seen few lytic bone lesions at uncommon locations. Bone tumours are not commonly found. If the presentation is at unusual site it is difficult to come to a conclusion. Inspite of availability of modern diagnostic techniques it is difficult to analyse the nature of the disease process. Histopathology is considered to be the gold standard for the diagnosis of these conditions causing lytic bone lesions.

Funding: No funding sources.

Conflict of interest: None declared.

\section{References}

1. V Popat, V Sata, D Vora, V Bhanvadia, M Shah, L Kanara; Role of Histopathology In Lytic Lesions Of Bone - A Study Of Seventy Cases Of Lytic Lesion Of Bone. Internet J Orthop Surg 2010;19(1).

2. Modi D, Rathod GB, Delwadia KN, Goswami HM. Histopathological study of bone lesions - A review of 102 cases. IAIM 2016;3(4):27-36.

3. Fabrizio Remotti, Frieda Feldman, Nonneoplastic Lesions That Simulate Primary Tumors of Bone. Arch Pathol Lab Med 2012;136:772-88.

4. Cancer.org (internet), Atlanta, American cancer society, Detailed guide, bone metastasis.

5. Manaster BJ. Tumors. In: Manaster BJ, Disler DG, May DA, eds. Musculoskeletal Imaging: The Requisites, 2nd edition, St. Louis, MO: Mosby; 2002, p. 1-104. 
6. Jain V, Makwana GE, Bahri N, Mathur MK. The "Dot in Circle" Sign on MRI in Maduramycosis: A Characteristic Finding. J Clin Imaging Sci 2012;2:66

7. Carroll DS. Mycetoma pedis. Radiol 1949;53:81-4.

8. Christopher D.M Fletcher, K.Krishnan Unni, Fredrik Mertens, World health organization classification of tumours, Pathology and genetics of tumours of soft tissue and bone, Bone tumours, 2002.

9. C Pamecha, JG Patel, LN Patel, PR Patel. Aneurysmal bone cyst of clavicle: 2004;14(2):179-80.

10. Elias J Anaisse, Michael R Mc Ginnis, Michael A Pfaller, Clinical mycology, Second edition, 500-23.
11. Juan Rosai, Rosai and Ackerman's. Surgical Pathology. $10^{\text {th }}$ edition. Elsevier;2011.

12. Mills SE. Sternberg's Diagnostic surgical pathology. $5^{\text {th }}$ edition. Lippincott Williams \& Wilkins. 2010.

13. Jasvir S. Khurana,Edward F. McCarthy, Paul J. Zhang; Essentials in Bone And Soft Tissue Pathology; 2010.

How to cite this article: Shivshetty S., V. Ramya, M Anita., Patil A. Rare lytic lesions of bone at uncommon locations-A study of 12 cases. J Diagn Pathol Oncol 2018;3(4):268-73. 